\title{
OBTENÇÃO E CARACTERIZAÇÃO DE FILMES À BASE DE BLENDA DE AMIDO E PECTINA DE ALTA METOXILAÇÃO
}

\author{
Vanessa da Silva $^{1}$; Geany Peruch Camilloto ${ }^{2}$ Terceiro Autor ${ }^{3}$ e Quarto Autor ${ }^{4}$ \\ 1. Bolsista PIBIC/CNPq, Graduanda em Engenharia de Alimentos, Universidade Estadual de Feira de Santana, e- \\ mail: nessasilva_sc@hotmail.con \\ 2. Orientador, Departamento de Tecnologia, Universidade Estadual de Feira de Santana, e-mail: \\ geanyperuch@yahoo.com.br
}

PALAVRAS-CHAVE: filmes; blenda; biopolímeros.

\section{INTRODUÇÃO}

Dentre os maiores problemas ambientais relacionados à utilização de materiais poliméricos, tais como o polipropileno, poliestireno, polietileno e poli(cloreto de vinila) pode ser destacado o tempo necessário para que ocorra degradação e a utilização de recursos não renováveis derivados do petróleo (OTAKE et al., 1995).

Diante disso, a utilização de polímeros de fontes renováveis vem sendo amplamente estudada nas indústrias de embalagens. Polímeros naturais são, em geral, biodegradáveis, biocompatíveis e podem ser obtidos a custos relativamente baixos (MORAES, 2010).

A fim de se obter materiais com melhores características, misturas físicas (blendas) de biopolímeros podem ser preparadas. Blendas poliméricas são misturas físicas de dois ou mais polímeros, resultando em uma mistura miscível ou imiscível. A mistura de polímeros é uma técnica que tem como objetivo a obtenção de materiais com propriedades diferentes às dos polímeros puros, sendo que esta mistura frequentemente exibe propriedades superiores quando comparadas às propriedades de cada componente polimérico individualmente. A principal vantagem das blendas é a simplicidade da preparação e fácil controle das propriedades físicas com a mudança das concentrações dos componentes (AMORIM, 2004).

Geralmente, o processo de obtenção de materiais a partir de misturas de polímeros é mais fácil e menos dispendioso do que a obtenção de novos polímeros. A habilidade para a produção de misturas que apresentem uma melhor combinação de propriedades em relação aos componentes individuais depende principalmente da compatibilidade do sistema (BONA, 2007).

Com o objetivo de melhorar as propriedades mecânicas e de barreira de filmes à base de biopolímeros, foi proposto um estudo de otimização da concentração de amido e pectina de alta metoxilação para obtenção de filmes biopoliméricos, uma vez blendas permitem a combinação das propriedades de cada componente da mistura, resultando em materiais com características não encontradas nos polímeros isolados.

\section{METODOLOGIA}

Foram elaborados filmes à base de blendas de amido de mandioca e pectina de alta metoxilação. As proporções dos biopolímeros para obtenção das blendas foram obtidas de acordo com o delineamento de mistura binário (Tabela 1).

Tabela 1 - Proporção dos biopolímeros para produção das blendas

\begin{tabular}{lcc}
\hline Filmes & $\%$ do gel de AMIDO & $\%$ do gel de PAM \\
\hline $\mathrm{A}$ & 0 & 100 \\
\hline
\end{tabular}




\begin{tabular}{lcc}
\hline B & 25 & 75 \\
$\mathrm{C}$ & 50 & 50 \\
$\mathrm{D}$ & 75 & 25 \\
$\mathrm{E}$ & 100 & 0 \\
\hline
\end{tabular}

A solução filmogênica de amido foi preparada por meio de agitação da suspensão aquosa do polímero $(5 \% \mathrm{~m} / \mathrm{v})$ contendo $30 \%(\mathrm{~m} /)$ de glicerol sob aquecimento à $70^{\circ} \mathrm{C}$ por 3 minutos. Para preparo da solução filmogênica de pectina de alta metoxilação, uma suspensão do polímero $5 \%(\mathrm{~m} / \mathrm{v})$ contendo $30 \%(\mathrm{~m} / \mathrm{m})$ de glicerol foi submetida a agitação em Turrax a $1500 \mathrm{rpm}$ por $35 \mathrm{~min}$ em temperatura ambiente.

As soluções filmogênicas de cada biopolímero foram misturadas nas proporções indicadas na Tabela 1, e submetida a banho ultrassônico durante 180 minutos para remoção de bolhas. Os filmes foram obtidos por processo "casting", onde as soluções filmogênicas foram espalhadas em placas de vidro e colocadas para secar à temperatura ambiente. Todas as formulações foram produzidas em três repetições.

Os filmes de cada ensaio foram submetidos análise de espessura e propriedades mecânicas (resistência a tensão, porcentagem de alongamento na ruptura e módulo de elasticidade), permeabilidade ao vapor de água e solubilidade.

A espessura dos filmes foi medida em 30 pontos diferentes com o auxílio de um micrômetro da marca Mitutoyo, com precisão de $0,01 \mathrm{~mm}$. A espessura foi expressa em micrômetros $(\mu \mathrm{m})$.

As propriedades mecânicas dos filmes foram determinadas utilizando-se 0 Texturômetro TA.XT Plus, com célula de carga de $50 \mathrm{~kg}$, velocidade e distância de separação entre as garras de $5 \mathrm{~mm} \cdot \mathrm{min}^{-1}$ e $50 \mathrm{~mm}$, respectivamente. Para cada filme, foram analisadas dez amostras com dimensões de $20 \mathrm{~mm}$ x $100 \mathrm{~mm}$ (ASTM, 2009).

A permeabilidade ao vapor de água dos filmes (PVA) foi determinada por meio do método dessecante, segundo a metodologia ASTM E 96 (ASTM, 2000).

Os resultados obtidos foram analisados com o auxílio do programa Statistical Analysis System (SAS), versão 9.1

\section{RESULTADOS E/OU DISCUSSÃO}

A espessura média dos filmes produzidos foi de $63,08 \pm 13,57 \mu \mathrm{m}$. O elevado desvio-padrão deve-se ao processo de produção manual dos filmes, que impossibilita o controle da força de espalhamento das soluções filmogênicas nas placas de vidro.

A espessura média dos filmes produzidos foi de $63,08 \pm 13,57 \mu \mathrm{m}$. O elevado desvio-padrão deve-se ao processo de produção manual dos filmes, que impossibilita o controle da força de espalhamento das soluções filmogênicas nas placas de vidro.

Os resultados de resistência máxima a tração (RMT e porcentagem de alongamento na ruptura (AR) dos filmes obtidos estão apresentados na Tabela 2.

A blenda da formulação B não gerou filmes homogêneos, apresentando regiões com separação de fases, provavelmente pela incompatibilidade das matrizes poliméricas nesta proporção. Os demais filmes apresentaram-se contínuos, transparentes e de fácil manuseio. Só foi observada incompatibilidade visual na formulação de blenda contendo maior proporção de pectina em relação ao amido (filme B).

De acordo com Garbim (2013), as blendas que apresentam total incompatibilidade, não ocorre interação entre os materiais, percebe-se a presença de duas fases e propriedades não-homogêneas em sua extensão. 
Tabela 2 - Efeito da composição da blenda polimérica sobre a resistência máxima a tração (MPa) e Alongamento na ruptura (\%) dos filmes.

\begin{tabular}{ccc}
\hline Tratamento & $\begin{array}{c}\text { Resistência Máxima a } \\
\text { Tração }(\mathrm{MPa})\end{array}$ & $\begin{array}{c}\text { Alongamento na } \\
\text { ruptura (\%) }\end{array}$ \\
\hline A & $15,50 \pm 4,77 \mathrm{~b}$ & $13,64 \pm 2,89 \mathrm{~b}$ \\
C & $5,38 \pm 1,99 \mathrm{c}$ & $25,33 \pm 3,16 \mathrm{a}$ \\
D & $22,72 \pm 1,67 \mathrm{a}, \mathrm{b}$ & $6,26 \pm 0,56 \mathrm{c}$ \\
E & $27,35 \pm 4,71 \mathrm{a}$ & $4,93 \pm 0,54 \mathrm{c}$
\end{tabular}

Médias seguidas da mesma letra nas colunas não diferem entre si ao nível de 5\% de probabilidade pelo teste Tukey.

A resistência máxima a tração dos filmes A, C e E diferiram entre si ( $\mathrm{p}<0,05)$, sendo que o filme $\mathrm{E}$, formado exclusivamente de amido, apresentou maior valor de RMT. O filme C, composto pela blenda dos dois polímeros na proporção de 1:1, obteve o menor valor de RMT, o que indica que não houve interações intermoleculares entre os polímeros, em ração da incompatibilidade entre os mesmos, o que pôde ser observado visualmente na formulação $B$. Os resultados indicam que filmes de pectina são menos resistentes que filmes de amido, e que a blendas destes polímeros não é favorável.

Em relação à porcentagem de alongamento na ruptura, os filmes $\mathrm{D}$ e $\mathrm{E}$ não diferiram entre si $(p>0,05)$, mas diferiram $(p<0,05)$ dos demais $(A$ e C). Diante do resultado, podemos caracterizar o filme de amido (E) com frágil. Segundo Dalcin (2007), materiais frágeis rompem-se com alongamento tipicamente menor do que $5 \%$ e mostram maior resistência mecânica.

Uma resistência a tração elevada em blendas poliméricas indica boa adesão na interface polímero/carga. Uma fratura com alongamento elevado indica que a força de tração está sendo transferida para a base polimérica (TAGUET, 2014).

Para avaliação da permeabilidade ao vapor de água (PVA), o filme E não foi incluído, pois apresentou trincas nas condições do teste. Ao avaliar as formulação A, C e D, observou-se que a composição da blenda não influenciou a permeabilidade ao vapor de água dos filmes, sendo a média da PVA de 4,31 $\pm 0,95$ g. $\mu \mathrm{m} \cdot \mathrm{m}^{-2} \cdot \mathrm{dia}^{-1} \cdot \mathrm{kPa}^{-1}$.

Segundo Pelissari et al (2009) citado por Horn (2012) a obtenção de blendas formadas pela mistura de biopolímeros tem a propriedade de melhorar as características físicas, químicas e mecânicas, pois os componentes das blendas são escolhidos de forma a compensar a deficiência do outro, e vice-versa. Os filmes de amido são geralmente quebradiços, requerem o melhoramento de propriedades mecânicas e são muito solúveis em água.

De acordo Horn (2012) as propriedades mecânicas e de barreira dos filmes são fortemente dependentes tanto da natureza dos biopolímeros utilizados como também das composições finais preparadas pela mistura com os plastificantes. A permeabilidade através de um filme indica a facilidade que um soluto migra de uma face em contato com uma parte do filme, em relação à outra face de contato com a outra parte do filme. Assim, a permeabilidade é o produto da difusividade pela solubilidade de soluto no filme. Alguns fatores influenciam a permeabilidade dos filmes, como a concentração dos plastificantes, a morfologia dos filmes, as características das moléculas permeante, no caso a água, e também as interações entre as cadeias poliméricas. Outro fator que deve ser levado em consideração é a espessura dos filmes, devido a mudanças estruturais causadas pelo intumescimento do filme, que afeta a estrutura interna que pode influenciar a permeação 


\section{CONCLUSÃO}

Não foi

possível realizar o estudo de otimização da composição da blenda de amido de mandioca e pectina de alta metoxilação, uma vez que algumas formulações propostas pelo delineamento experimental não geraram filmes homogêneos impedindo a caracterização dos mesmos.

A obtenção de filmes à base das blendas de amido de mandioca e pectina de alta metoxilação não permitiu melhorias nas propriedades mecânicas e de barreira dos filmes, provavelmente em função da incompatibilidade entre as matrizes poliméricas. Os filmes obtidos dos polímeros isolados apresentaram melhores propriedades mecânicas quando comparados aos filmes obtidos das blendas.

Sugere-se

novos teste visando a mistura de outros polímeros ou uso de compatibilizantes para obtenção de materiais com propriedades adequadas para uso como embalagens de alimentos.

\section{REFERÊNCIAS}

AMORIM, A. M. Estudo da miscibilidade de blendas de poli(óxido de etileno) e poli(succinato de etileno). Dissertação de Mestrado. Departamento de Química. Universidade Federal de Santa Catarina, Florianópolis, 2004.

ASTM - American Society for Testing and Materials. (2009). Standard Test Method for Tensile Properties of Thin Plastic Sheeting. D882-09. Philadelphia.

ASTM - American Society Standard Testing and Materials. (2000). Standard test method for water vapor transmission of materials. E 96-00. Philadelphia.

BONA, J. C. Preparação e caracterização de filmes biodegradáveis a partir de blendas de amido com polietileno. Dissertação (Mestrado em Engenharia de Alimentos), Universidade Federal de Santa Caratina, Florianópolis, 2007.

DALCIN, G. B. Ensaio dos Materiais. Curso de Engenharia Industrial Mecânica. Universidade Regional Integrada do Alto Uruguai e das Missões. Disponível em: http://www.urisan.tche.br/ lemm/arquivos/ensaios_mecanicos.pdf. Acesso em: 05 de agosto de 2018.

GARBIM, V. J. (2003). Polimeros termoplásticos - aditivos de compatibilidade e agentes de acoplamento. 2013. Disponível em https://pt.slideshare.net/Borrachas/aditivos-compatibilizacao-acoplamento. Acesso em: 05 de agosto de 2018.

HORN, M. M. Blendas e filmes de quitosana/amido de milho: Estudo da influência de adição de polióis, oxidação do amido e razão amilose/amilopectina nas suas propriedades. Tese (Doutorado) - Curso de Química, Universidade de São Paulo, São Carlos, 2012. $147 \mathrm{f}$.

MORAES, M.A. Obtenção e caracterização de blendas e compósitos poliméricos de fibroína de seda e alginato de sódio. Dissertação (Mestrado em Engenharia Química), Faculdade de Engenharia Química, Universidade Estadual de Campinas, Campinas, 2010.

OTAKE, Y.; KOBAYASHI, T.; ASABE, H.; MURAKAMI, N.; ONO, K. J. Biodegradation of low- density polyethylene, polystyrene, polyvinyl chloride, and urea 
formaldehyde resin buried under soil for over 32 years. Applier Polymer Science, v. 56, p. 1789-1796, 1995.

TAGUET, A., CASSAGNAU, P., \& CUESTA, J. Structuration, selective dispersion and compatibilizing effect of (nano)fillers in polymer blends. Progress in Polymer Science, v. 39, n. 3, p. 435-444, 2014. 